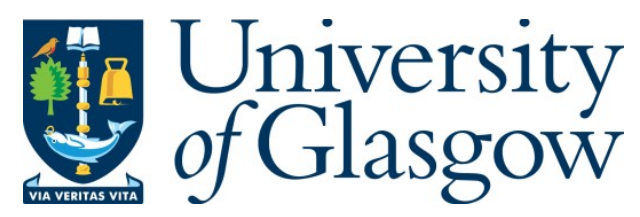

Carter, J. A. (2014) Relativism, knowledge and understanding. Episteme, 11(1), pp. 35-52.

There may be differences between this version and the published version. You are advised to consult the publisher's version if you wish to cite from it.

http://eprints.gla.ac.uk/132389/

Deposited on: 6 December 2016

Enlighten - Research publications by members of the University of Glasgow http://eprints.gla.ac.uk 


\title{
Relativism, Knowledge and Understanding ${ }^{1}$
}

\author{
J. ADAM CARTER \\ Eidyn Research Centre \\ University of Edinburgh \\ j.adam.carter@ed.ac.uk
}

\begin{abstract}
The arguments for and against a truth-relativist semantics for propositional knowledge attributions (KTR) have been debated almost exclusively in the philosophy of language. But what implications would this semantic thesis have in epistemology? This question has been largely unexplored. The aim of this paper is to establish and critique several ramifications of KTR in mainstream epistemology. The first section of the paper develops, over a series of arguments, the claim that MacFarlane's (2005; 2010) core argument for KTR ultimately motivates (for better or worse) the extension of a truthrelativist semantics to a subset of understanding attributions-attributions of understandingwhy. I conclude by presenting some reasons to think that even if KTR were otherwise plausible, a truth-relativist semantics for understanding-why attributions is not. These claims, taken together, constitute a kind of epistemological argument against MacFarlanestyle truth-relativism for knowledge attributions.
\end{abstract}

\section{Introduction}

Over the past decade, truth-relativist semantics have gained popularity for several areas of discourse. These areas include discourse about predicates of personal taste (Lasersohn 2005; Kölbel 2003), epistemic modals (Egan 2007; Egan, Hawthorne \& Weatherson 2007; MacFarlane 2011), future contingents (MacFarlane 2003), indicative conditionals (Weatherson 2006) gradable adjectives (Richard 2004), and knowledge attributions (Richard 2008; MacFarlane 2005; 2010).

Positions under the description of "knowledge relativism"-though by no means popular ${ }^{2}$ within mainstream epistemology-have nonetheless typically been defended on the basis of straightforwardly epistemic considerations, often by appeal to some kind of "epistemic incommensurability" thesis ${ }^{3}$. The considerations that motivate a truth-relativist semantics for

\footnotetext{
${ }^{1}$ Thanks to Christoph Kelp, Aidan McGlynn, Mikkel Gerken, Emma C. Gordon, Philip Nickel, Duncan Pritchard, Brian Rabern, and Anders J. Schouybe for helpful comments on this paper. Thanks also to an audience at KU-Leuven and to two anonymous referees at Episteme, with special thanks to the Associate Editor.

${ }^{2}$ See Boghossian (2006) for an example of some common lines of defense against the epistemic relativist.

${ }^{3}$ Following here Pritchard (2010), we can usefully think of the epistemic incommensurability thesis distinctive of common forms of epistemic relativism (e.g. Hacking (1982); Rorty (1995)), as the claim that "It is possible for two agents to have opposing beliefs which are rationally justified to an equal extent where there is no rational basis by which either agent could
} 
knowledge ascriptions (KTR), on the other hand, are entirely different: they are distinctly semantic, and the form of knowledge relativism that emerges, and which has been defended with the most sophistication by MacFarlane $(2005,2010)$, is thus a strikingly different kind of beast than the more traditional forms of epistemic relativism epistemologists are used to. Accordingly, truth-relativism about knowledge attributions (hereafter, KTR)-despite the interest it has generated with semanticists-has been for the most part unexplored insofar as the thesis has ramifications for debates within mainstream epistemology.

Put roughly, what KTR says is that (for example) the utterance "Monroe knows that the spice shop is open" can be true relative to the epistemic standards Nick employs when assessing this proposition as true or false, while at the same time, false relative to the epistemic standards Juliet employs when she assesses the proposition as true or false $\mathrm{e}^{4}$. The epistemic standards relevant to the truth of the utterance are those that feature in the context in which the proposition is being assessed as true or false, as opposed to ( $a$ la attributor contextualism) the context in which the utterance is made ${ }^{5}$.

A feature of MacFarlane's view is that, without the specification of an epistemic standards parameter with reference to which the expression "Monroe knows that the spice shop is open" is assessed, "Monroe knows that the spice shop is open" lacks an extension (and thus, is neither true or false) much in the same way that, a la Kaplan, "I am here now" lacks an extension out with the specification of a time and a world ${ }^{6}$. MacFarlane takes his manner of relativizing knowledge attributions to epistemic standards to be no more objectionable ${ }^{7}$ in principle than the Lewis-Kaplan relativization of utterance truth to worlds and times (though, see Cappelen \& Hawthorne (2010) for a sustained objection on this point).

What I want to explore here is-apart from whether KTR holds up by the criteria of semanticists-what are the ramifications of KTR in epistemology? The first section of the paper develops, over a series of arguments, the claim that MacFarlane's core argument for KTR ultimately

properly persuade the other to revise their view." As an aside, it's worth noting that while ontological relativism (a la Quine and Putnam) has epistemological ramifications, the kind of relativism developed by Quine and extended by Putnam is not epistemic, per se. On this point, see Baghramian (2004).

${ }^{4}$ As MacFarlane (2010: 2) puts it: "The accuracy of an assertion or belief depends on the epistemic standard that is relevant at the context of assessment. Thus, there is no "absolute" answer to the question whether such an assertion or belief is accurate; accuracy is an assessment-sensitive matter."

${ }^{5}$ These contexts will (of course) be the same when the context in which the target knowledge attribution is being evaluated is the same context as that in which it was made.

${ }^{6}$ See here MacFarlane (2007: 6-7).

${ }^{7}$ Cappelen \& Hawthorne (2010) nicely capture the reasoning underlying this point in their presentation of the truthrelativist's position they criticize in their monograph under the description of "analytic relativism": "Contemporary Analytic relativists reason as follows: 'Lewis [1980] and Kaplan [1989] have shown that we need to relativize truth to triples of <world, time, location $>$. Hence in a way, anyone who follows Lewis and Kaplan is already a relativist. There are only truth and falsity relative to settings along these three parameters, and so there is no such thing as truth simpliciter. But, having already started down this road, why not exploit these strategies further? In particular, by adding new and exotic parameters into the circumstances of evaluation, we can allow the contents of thought and talk to be non-specific (in Kaplan's sense) along dimensions other than world, time and location. (Cappelen \& Hawthorne 2010: 10) 
commits him to extending (for better or worse) a truth-relativist semantics to a subset of understanding attributions-attributions of understanding-why. In order to make this case, I engage with recent work on the connection between propositional knowledge and the related epistemic states of knowledge-how and understanding. I conclude by presenting some reasons to think that even if KTR were otherwise plausible, a truth-relativist semantics for understanding-why attributions is not.

If the first argument is sound, then we will have gained some ground tracing out an upshot of KTR in epistemology. If the second argument is sound, then even if the truth-relativist about knowledge attributions wins the day on semantic grounds (a point I will not be weighing in on ${ }^{8}$ ), this fact won't suffice as a defense of the view.

\section{$\$ 1$. MacFarlane's core argument for truth-relativism for knowledge attributions applies, mutatis mutandis, to understanding-why attributions}

In $₫ 1.1$, I briefly outline the key steps in MacFarlane’s argument for KTR. In $₫ 1.2$, I show how the line of argument MacFarlane advances for KTR-an argument initially framed vis-à-vis propositional knowledge, motivates mutatis mutandis truth relativism for knowledge-how ascriptions (and this is shown to be so regardless of whether one is an intellectualist about knowledge-how). In \$1.3 I argue that there is a variety of understanding-understanding-why-for which (on three prominent accounts of understanding-why-(i) the traditional causal model, (ii) Grimm's ability model, and (iii) Pritchard's cognitive achievement model) either propositional knowledge or knowledge-how is an essential ingredient, and argue accordingly that a pairing of KTR with a non-truth-relativist semantics for understanding-why ascriptions will be untenable. Accordingly, $\$ \$ 1.1-1.3$ constitute a combined argument for the claim that MacFarlane's argument for KTR motivates an extension (for better or worse) of his truth-relativist semantics to understanding-why ascriptions. Let's now take these steps in turn.

\section{\$1.1 MacFarlane's core argument for truth-relativism for knowledge attributions}

MacFarlane has twice argued $\left(2005^{9}, 2010\right)$ for $\mathrm{KTR}^{10}$. A core thread of argument that spans both defenses of KTR is a kind of synthesis argument, whereby a truth-relativist semantics for knowledge

\footnotetext{
${ }^{8}$ It is worth noting that the truth-relativist doesn't obviously preserve disagreement, as is claimed. More specifically, MacFarlane's semantic argument for truth-relativism about knowledge ascriptions relies on the claim that disagreement over the truth-relativist's standards-neutral semantic content is genuine disagreement. See Dreier (2009), Francen (2010) and Carter (2013) for some arguments against the truth-relativist on this point.

${ }^{9}$ MacFarlane's (2005) early and most detailed position is a combination of a negative argument and a positive argument. The negative argument begins with an identification of a set of linguistic data-(i) the variability of epistemic standards; (ii) embedded occurrences of 'know', and (iii) truth ascription/retraction data, and reasons as follows: Strict invariantism can explain (ii) and (iii) but fails to explain (i). Subject sensitive invariantism (SSI), on the other hand, can explain (i) and (iii) but not (ii). A contextualist semantics explains (i) and (ii), but not (iii). MacFarlane argues further that none of the considered positions can effectively explain away its failure to preserve one of (i)-(iii) by appealing to pragmatics or by attributing
} 
attributions is presented as preserving the virtues of invariantist and contextualist semantics for knowledge attributions whilst avoiding troublesome semantic objections facing each position, respectively. The synthesis argument runs against the backdrop of two linguistic data points; firstly, linguistic data supports a variation in the epistemic standards one must meet to qualify as knowing; secondly, linguistic data (e.g. retraction data) supports the recognition of genuine disagreements about the correctness of knowledge attributions.

Traditional (classic) invariantists, according to whom the semantic value of knowledge attributions is invariant across contexts of use (and across circumstances of evaluation), can easily make sense of disagreement data ${ }^{11}$. However, traditional invariantism notoriously has problems explaining the (epistemic-standards) variation data (e.g. that the epistemic credentials required for an agent to count as knowing are, as reflected by use, strict in high-stakes cases, lax in low-stakes cases). Classic (attributor) contextualism ${ }^{12}$ is, of course, tailor made to accommodate the standards variation data. But, argues MacFarlane, a semantic objection facing all versions of contextualism ${ }^{13}$ about knowledge attributions is that such views explain the variation data only on by way of giving up ${ }^{14}$ semantic conflict necessary for disagreement. This is taken to be problematic because discourse about knowledge ascriptions is discourse where (unlike discourse featuring ordinary indexicals ${ }^{15}$ ) disagreement seems genuine. Here's MacFarlane:

If Joe (in a low standards situation) says, "I know that the bank is open on Saturday," and Sarah later says (in a high standards situation), "You didn't know that the bank was open," Joe will naturally take Sarah's claim as a challenge to his own, and either defend his claim or withdraw it. We do not expect him to say (as the contextualist account would suggest he

semantic blindness. The threat of the negative argument is eliminativism. The positive argument claims that we can avoid eliminativism by defending a semantics that can explain (i)-(iii), and further, that a truth-relativist semantics successfully preserves (i)-(iii).

${ }^{10}$ MacFarlane's most recent work on the topic is actually a rough draft of a chapter entitled "Knows", to be included in his monograph project Assessment Sensitivity: Relative Truth and its Applications; however, MacFarlane describes his draft as still being heavily revised, and so "Knows" is not currently in a finished state.

${ }^{11}$ Disagreements where, for instance, " $S$ knows that $p$ " is asserted by one party and denied by another are no more problematic to explain as genuine disagreements by the traditional invariantist than are other everyday cases of disagreement featuring semantic conflict.

${ }^{12}$ Contextualists about knowledge hold, following DeRose (1995) here, that "how strong a subject's epistemic position must be to make true a speaker's attribution of knowledge to that subject is a flexible matter that can vary according to features of the speaker's conversational context" (DeRose 1995: 29).

${ }^{13}$ This includes non-indexical contextualism. See MacFarlane (2009b).

${ }^{14}$ As Baker (2012) puts it, in a discussion of the claim that contextualists lose disagreement: the challenge typically stems from the thought that "there can be no disagreement where there is no semantic conflict between assertions"(Baker 2012: 111)

${ }^{15}$ Cf. discourse involving typical indexicals (e.g. "tall" and "flat") where apparent disagreement typically turns out to be superficial. 
should): "Yes, you're right, I didn't know. Still, what I said was true, and I stick by it. I only meant that I knew-by-low-standards." (MacFarlane 2010: 10; my italics).

In short, then: contextualists can't explain disagreement, even though they can explain the standards variation data. So disagreement data is a problem for contextualism. Traditional invariantists can explain disagreement, though they can't explain the standards variation data. So standards variation data is a strike against traditional invariantism. Subject-sensitive (as opposed to traditional) invariantism-according to which the relevant epistemic standards are those that feature in the Kaplanian circumstances of evaluation-can explain both standards variation data and disagreement data, but only on pain of making counterintuitive predictions in cases of temporal and modal embedding ${ }^{16}$.

Against the background of these problems facing invariantism and contextualism, vis-à-vis the preservation of standards variation data and disagreement data, MacFarlane says that the truthrelativist offers a way to have it all. By making knowledge-ascriptions assessment-sensitive ${ }^{17}$, the truthrelativist preserves (unlike the invariantist) the insight that the accuracy of these ascriptions depends in part on the contextually relevant standards, and (unlike the contextualist) preserves disagreement by denying that the standard relevant to whether a knowledge ascription is accurate, is the standard at play in the context in which the utterance is made-rather, it's the standard at play in the context in which it is assessed as true or false (MacFarlane 2009: 1). Moreover, unlike the SSIist, the truthrelativist does not make counterintuitive predictions in temporally and modally embedded contexts ${ }^{18}$. So we needn't be eliminativists ${ }^{19}$ - truth-relativism offers a semantics that explains the linguistic data without any ugly remainder. This is the rough shape of MacFarlane's "synthesis" argument.

\section{$\$ 1.2$ Implications in epistemology: knowledge-how ascriptions}

MacFarlane concludes his recent (2009) defense of KTR with a section entitled "Questions for the Relativist." One question he asks, in light of his recommendation to extend a truth-relativist semantics for "know" is: "are there other expressions for which a relativist treatment is needed? How does know relate to them?" (MacFarlane 2009: 16). A more specific version of this question is: if "know" gets a

\footnotetext{
${ }^{16}$ Consider here the case of modal embedding: “I don't know whether the bank is open on Saturdays, but if I didn't really need the money on Sunday, I would know"(MacFarlane 2009: 14). SSI awkwardly predicts that statements like this can come out true. In cases of temporal embedding, SSI generates the strange result that "Joe doesn't know that the bank is open on Sundays, but five minutes ago, before he learned that he would have to pay for emergency surgery on Sunday, he did know that it is open on Saturdays" (MacFarlane 2009: 14). (cf. Blome-Tillmann (2009) for more detailed discussion of these cases.) ${ }^{17}$ This is MacFarlane's preferred term for a truth-relative semantics. He uses the terms interchangeably.

${ }_{18}$ MacFarlane (2005) points out that these predictions are a direct result of making (as the SSIist does) knowledge attributions circumstance-variable. Because the truth-relativist opts for assessment rather than circumstance variability, the problematic predictions in temporal and modal embedding cases do not arise.

${ }^{19}$ This is the (unwanted) option MacFarlane claims we are left with if no semantics for 'knows' can preserve the linguistic data supported by use. See $f n$. 4 .
} 
truth-relativist semantics, then since knowledge relates intimately with other epistemic concepts, do any other epistemic concepts need a relativist treatment?

An initial place to look would be especially tight conceptual connections. Take, as an example case, Williamson's (2000) knowledge-evidence equivalence: $\mathrm{E}=\mathrm{K}$. Suppose, for reductio, that $\mathrm{E}=\mathrm{K}$, and further, that the truth-conditions for $\mathrm{E}$ are not assessment sensitive, but the truth-conditions for $\mathrm{K}$, are. The resulting tension would be untenable (at best), at worst, contradictory. It seems that if Williamson is right that our evidence is what we know, then the truth-relativist about knowledge ascriptions will have (for better or worse) foisted upon her the view that evidence ascriptions are assessment-sensitive. This is an example of a kind of ramification MacFarlane's thesis might have in epistemology, albeit, it is a ramification in place only if you already make certain (unconventional ${ }^{20}$ ) assumptions about the relationship between knowledge and evidence ${ }^{21}$.

In this section I want to examine a ramification of MacFarlane's view that (unlike the example just considered) doesn't depend on previous theoretical commitments. Let's begin by noting that MacFarlane's argument is an argument framed in terms of propositional knowledge. The relationship between propositional knowledge and knowledge-how is a contentious topic on which epistemologists are deeply divided. Though, the dividing lines are pretty clear: intellectualists about knowledge-how (e.g. Stanley 2011; Stanley \& Williamson 2001) reduce ${ }^{22}$ knowledge-how to propositional knowledge (knowledge-that). This is an influential though recent trend; more traditionally, following Ryle (1946; 1949), knowledge-how is conceived of as kind of ability, the possession of which is not reducible to knowing some fact.

I want to suggest now that MacFarlane's argument for truth relativism for propositional knowledge motivates in equal measure truth-relativism for knowledge-how ascriptions regardless of whether one endorses an intellectualist (reductive) account of knowledge how. Consider first the simple leg of this claim: for anyone who already accepts an intellectualist reduction of knowledge-how to knowledge-that, truth-relativism about propositional knowledge attributions extends to truthrelativism about knowledge-how ascriptions (which are also propositional knowledge) ${ }^{23}$.

\footnotetext{
${ }^{20}$ See, for example, Weatherson (2009).

${ }^{21}$ Thanks to an anonymous referee for helpful suggestions in clarifying the strand of discussion.

${ }^{22}$ Stanley's account of knowledge how is an element of his intellectualist account of intelligent action. Like Ryle (1946; 1949), Stanley thinks actions have intelligence properties in virtue of their manifesting knowledge-how; unlike Ryle, though, Stanley thinks that action is intelligent in virtue of being guided by propositional knowledge, and that knowledge-how to $\phi$ is something one possesses when (to put it simply) there is a fact one knows of the following form: that $w$ is a way for one to $\phi$ (Stanley 2011: 122).

${ }^{23}$ For reductio, assume that (as the intellectualist does) $S$ knows how to $\phi$ just in case there is some proposition $\langle p\rangle$ that $S$ knows, but that the truth conditions for the latter are assessment sensitive, but not the former. That said, note that a demonstrative might make the expression in which it occurs context sensitive, even though the expression need not be context sensitive if we replace the demonstrative with the proper name it denotes. I am not assuming that terms that can be substituted in a context and have the same referent would each have the same implication for the truth conditions of the expression in which they occur. None of the examples I explore here turns on this issue.
} 
Suppose, however, that one denies ${ }^{24}$ intellectualism. Let's assume, ex hypothesi, the Rylean (1946; 1949) view: that "S knows how to $\phi$ " is true just in case there is some ability S possesses, as opposed to some fact S knows ${ }^{25}$. As it turns out, MacFarlane's 'synthesis' argument for truthrelativism about propositional knowledge ascriptions applies mutatis mutandis for knowledge-how ascriptions, even if knowledge-how is conceived of (contra the intellectualist) as a kind of ability (a la Ryle). To test this claim, let's check whether the truth-relativist's arguments vis-à-vis propositional knowledge apply mutatis mutandis for knowledge-how ascriptions by seeing whether discourse about know-how (conceived of as a kind of ability) supports (as did knowledge-that discourse) the recognition of both (i) varying standards for what counts as knowledge (how) and (ii) disagreement, supported by retraction data.

If knowledge-how discourse does have these characteristics, then MacFarlane's reasoning for needing a synthesis between contextualism and invariantism that motivated his truth-relativism about knowledge-that ascriptions extends mutatis mutandis to knowledge-how ascriptions.

Let's check first the matter of whether know-how discourse supports a semantics that recognizes contextually variant epistemic standards that must be met to count as knowing-how. Consider here a case: suppose that Almeida, a high school janitor, is an amateur bomb dismantler. He's read a few books on the subject and in his only attempt to dismantle a bomb-a bomb constructed by a depressed high-school student-Almeida was successful. Now consider two contexts, easy and hard, where replica in "Easy" and the bomb in "Hard" are the same kind of bomb:

Easy: Almeida is on a skills-challenge team, and the team must select one player to represent the team in the bonus round, where the challenge will be to dismantle a replica bomb.

Hard: Almeida fudged his credentials to be accepted into an elite U.S. bomb-squad for which 10 years intensive training is required. The U.S. squad sends Almeida on a special mission to dismantle a bomb at the U.S. Embassy in Tripoli. Once Almeida is inside the Embassy, the squad leader discovers Almeida’s actual credentials.

\footnotetext{
${ }^{24}$ I intend this point to include denials of intellectualism like Ryle's as well as stronger denials (e.g. Dreyfus 2005) of intellectualism, where know-how is conceived not only as non-propositional but also "non-conceptual" and "non-rational". ${ }^{25}$ As Glick (2012) points out, there is something of a middle ground between the strong anti-intellectualist position, according to which, universally, all know-how is propositional knowledge, and the Rylean view, according to which all know-how is ability-knowledge. Such a position has been defended by Hintikka (1975), and Glick also embraces this idea. I think Glick is right to suggest that many anti-intellectualists would be "satisfied with establishing that some know-how is not a kind of knowledge-that, at least so long as the kind of know-how in question was the kind present in standard examples used to motivate anti-intellectualism" (Glick 2012: 125).
} 
Again, assuming here ala Ryle that knowledge how is just a kind of ability, Easy and Hard support ${ }^{26}$ a variation in the strength of the ability one must possess if one is to count ${ }^{27}$ as knowing-how much as DeRose-style bank cases stand to support a variation in the epistemic standards one must meet to count as knowing-that. Accordingly, as the argument goes, the contextualist seems better suited than the invariantist to make sense of this apparent variation of standards at play in know-how discourse.

But, just as the contextualist struggles to countenance disagreement $v i s-\grave{a}$-vis propositional knowledge, the contextualist likewise struggles to countenance disagreement vis-à-vis knowledge-how. Modifying here MacFarlane's original example: if Almeida (in a low standards situation) says, "I know how to dismantle a bomb," and his friend says (in a high-standards situation), "You didn't know how to dismantle a bomb," Almeida will naturally take his friend's claim as a challenge to his own, and either defend his claim or withdraw $\mathrm{it}^{28}$.

Putting these results together: If you are an intellectualist about knowledge how, then, truthrelativism for propositional knowledge-attributions extends to knowledge-how attributions (as knowhow just is propositional knowledge). But, as I've shown, even if you reject intellectualism, and view know-how as an ability, the standards-variability and disagreement features of knowledge-how discourse are in place, and these are precisely the features that, the truth-relativist tells us, require us to embrace truth-relativism as a synthesis between contextualism and invariantism.

\section{$\$ 1.3$ Understanding and knowledge}

In this section I want to establish two things. Firstly, that there is an epistemic state, understanding$w h y$, for which either propositional knowledge or knowledge how (conceived as a kind of ability) is plausibly an essential ingredient; secondly, if this is right, then (given the result from \$1.2) KTR is going to be untenable when paired with a non-truth relativistic semantics for understanding-why.

\footnotetext{
${ }^{26}$ One might pause to consider whether the invariantist could explain away cases like this by offering some pragmatic explanation (e.g. Rysiew 2001) of the data or attributing speaker error (e.g. semantic blindness). MacFarlane (2005) argues that both skeptical and moderate invariantists will ultimately be unsuccessful in such attempts. And plausibly, his reasoning will be in place vis-à-vis the invariantist who tries to make the same kind of move to explain away variability data in cases of know-how.

${ }^{27}$ One might suggest that, in the hard context, Almeida doesn't fail to know how to dismantle a bomb, he rather 'knows how to do it, but just not very well.' Such a position recognizes Almedia as nonetheless knowing how to dismantle a bomb. In a context in which knowing how to dismantle a bomb is taken to involve training Almeida lacks, it's more plausible to suppose he will be simply denied knowledge-how in the high stakes case, as his ability fails to meet the relevant standard for knowhow, in that context.

${ }^{28}$ There is room to argue here that bomb case could also constitute support for the view that know-how is (contra Grimm) actually propositional knowledge, as the intellectualist supposes. (After all, as MacFarlane purports to have shown, propositional knowledge appears both sensitive to shifting stakes and is such that it admits of genuine disagreement.) Crucially, though, my suggestion here is that even if we assume, ex hypothesi, that knowledge-how is not (as the intellectualist insists) knowledge-that, then, given that know-how discourse admits of these two features (standards variability and disagreement), the truth-relativist's argument ( $v i s-\grave{a}-v i s$ propositional knowledge) motivates, by parity of reasoning, truthrelativism vis-à-vis knowledge-how-as these two features are present no less in know-how discourse. Thanks to the Associate Editor for drawing attention to this issue.
} 
Understanding, as an epistemic state ${ }^{29}$, has been discussed in the literature under two ${ }^{30}$ central varieties-which map on to the kinds of understanding we take ourselves to possess when we understand why such and such happened ${ }^{31}$, and when we understand some subject matter, respectively. Understanding-why ${ }^{32}$ - which has also been referred to by Pritchard as atomistic understanding - has as a representative example: "Jane understands why her house burnt down." Understanding-why is important not only in epistemology, but also in the philosophy of science ${ }^{33}$.

We can contrast this kind of understanding with what Kvanvig (2003) calls objectual understanding, or understanding that takes as its object a subject matter (e.g. Graham understands second-order logic). We'll now restrict our focus to understanding of the first varietyunderstanding-why. What is involved in understanding-why? This is an important question, but not one we need to take a stand on here. For the present purposes, what is important-in order to take stock of the truth-relativist's commitments in epistemology-is a more specific question: How is understanding-why connected to knowledge? There are three prominent views here.

On the traditional model of understanding-why (e.g. Lipton 2004, Kitcher 2002), which traces its roots to Aristotle, one understands why $\mathrm{x}$ just when one acquires knowledge of the cause of $\mathrm{x} \cdot{ }^{34}$ As Grimm (2011) points out, the standard way to interpret the knowledge condition here is propositional. On this propositional reading of the traditional model of understanding-why, one understands why $x$ just when one knows some relevant causal proposition that "specifies the causal relationship that holds between the explanandum and the explanans" (Grimm 2011).

It is easy to see that the truth-relativist about knowledge ascriptions will be committed (trivially) to embracing truth-relativism for understanding-why ascriptions, on the propositional reading of the traditional model of understanding-why. After all, on the propositional reading of the traditional model, understanding-why just is possessing a certain kind of propositional knowledge: knowledge of a relevant causal proposition. KTR is already committed to a truth-relativist semantics

\footnotetext{
${ }^{29}$ Another variety of understanding that is often referenced is linguistic understanding. It is controversial whether linguistic understanding should be viewed as a kind of epistemic state, or as a kind of disposition. See here Longworth (2008) for a helpful discussion on the relationship between linguistic understanding and knowledge.

${ }^{30}$ Cf. Kvanvig (2003, Ch. 8) and Gordon (2012) for arguments to the effect that the recognition of an epistemic state termed propositional understanding - is misguided. Gordon appeals to linguistic data to show that propositional understanding is not interestingly different from propositional knowledge (and so does not constitute a unique kind of understanding that deserves attention in epistemology.)

${ }^{31}$ Or, alternatively, why such and such is the case.

${ }^{32}$ Thanks to an anonymous reviewer for pointing out that objectual understanding and understanding-why don't exhaust the varieties of understanding supported by ordinary use, given that we also often refer to constructions of the form "understanding where" "understanding what", etc. Brogaard (2005) accordingly refers to the family of associated understanding constructions "understanding-wh." Understanding-why is a paradigmatic example of understanding-wh, and I am following Pritchard's convention of framing my discussion in terms of this state (which is also the focal variety of understanding in the literature on understanding in the philosophy of science).

${ }^{33}$ For some representative discussions of understanding-why in the philosophy of science, also referred to as explanatory understanding, see Lipton (2004), Kitcher (2002), de Regt, (2009) and Khalifa (2013).

${ }^{34}$ This position is also in line with Lewis's (1986) thinking.
} 
for propositional causal knowledge attributions. But, this is just one of three prominent models of understanding-why. I want to go further now and suggest that MacFarlane's defense of KTR motivates the extension of a truth-relativist semantics for understanding-why also on the two other prominent models of understanding-why which have been defended in recent work by Stephen Grimm (2011) and Duncan Pritchard (2010), respectively. It will be a straightforward matter (given the results from $\$ 1.2)$ to make the point for Grimm's view, less so for Pritchard's.

Grimm (2011) argues that the traditional causal model of understanding-why is (contrary to recent criticisms by Pritchard ${ }^{35}(2010)$ ) correct, but only on an ability, rather than a propositional, reading of the knowledge condition. As Grimm sees it, understanding-why is knowledge of causes, but in a way that is strictly non-propositional: the knowledge of causes that is relevant for understanding is instead a know-how that consists in the ability to grasp a non-propositional object, which is the relatedness of causal terms ${ }^{36}$.

Given the result from the previous section - that MacFarlane, in motivating KTR, motivates a truth-relativist semantics for knowledge-how (conceived of either propositionally or as an ability), then on an account of understanding-why (such as Grimm's) that reduces understanding-why to know-how, understanding-why just is a kind of know-how, and so must be given a truth-relativist treatment no less than knowledge-how is given a truth-relativist treatment. This will be case as well for accounts of understanding-why that reject the traditional model of understanding-why as knowledge of causes, whilst nonetheless identifying understanding-why with know-how ${ }^{37}$.

Pritchard (2010), on the other hand, defends what can be called the cognitive achievement view of understanding-why. On Pritchard's view, there are cases of genuine understanding-why where the relevant knowledge is lacking, and cases where the relevant knowledge is present but understanding is lacking (Pritchard 2010: 1). What is essential to understanding-why, for Pritchard, is not causal knowledge but cognitive achievement, where cognitive achievement is understood as a cognitive success that is primarily attributable to one's cognitive ability ${ }^{38}$.

We can set aside Pritchard's reasons for thinking causal knowledge is not sufficient for understanding-why (as such an argument wouldn't establish that knowledge is not essential to

\footnotetext{
${ }^{35}$ Hills (2009) also has recently challenged the propositional model of the traditional view of understanding-why-on grounds similar to Pritchard's (2010) — though her argument is aimed specifically at moral understanding.

${ }^{36}$ To appreciate the motivation for his argument, it's helpful to briefly consider an analogy he appeals to in the case of a priori knowledge. Grimm (2011) points out that merely assenting to a necessary truth is insufficient for knowing that necessary truth a priori. What is needed is also that I see or grasp the necessity itself. Grimm argues that what is grasped or seen (when we grasp or see a priori) is not a proposition but a modal relationship between properties (or objects, or entities). Cleverly, Grimm applies this model for what is involved in 'knowledge of necessary truths' to the arena of understanding, which he thinks involves a kind of 'seeing or grasping, of the terms of the causal relata, their modal relatedness.'

${ }^{37}$ Grimm identifies Zagzebski (2001) De Regt and Dieks (2005), as well as de Regt (2009) as examples of defenses of understanding-why as a kind of know-how, though not on the traditional model.

${ }^{38}$ Pritchard has argued in a number of recent works (e.g. Pritchard 2010a, 2010b, 2012) that cognitive achievement is neither necessary nor sufficient for knowledge.
} 
understanding-why), and focus on his argument for denying that causal knowledge is necessary for understanding-why.

His argument turns on two observations about environmental epistemic luck, which is the kind of epistemic luck widely taken by epistemologists to undermine knowledge in barn façade cases-cases where one's belief (though properly formed) could easily have been false for reasons due exclusively to the epistemically inhospitable nature of one's environment. Pritchard's observations are, first, that environmental epistemic luck is incompatible with propositional knowledge, and secondly, that it is compatible with understanding-why. Thus: you can have understanding-why in a case where your would-be causal knowledge is undermined by environmental luck, rendering knowledge of the relevant causal proposition unnecessary for understanding-why.

To clarify his reasoning, Pritchard has us suppose a scientist, Kate, is using an instrument to try to understand why a chemical reaction occurred. Suppose the instrument malfunctions but nonetheless registers the correct result (namely, that oxygen caused the reaction). This is akin to a standard Gettier case, where luck intervenes between the agent and the fact. Accordingly, here, Kate fails to know that oxygen caused the chemical reaction, and Pritchard suggests she also fails to understand why the reaction occurred (as one can't attain understanding-why via the use of malfunctioning equipment.) Now here's Pritchard's twist: suppose we change the case so that the instrument does not malfunction, but easily could have, i.e. the instrument malfunctions in most nearby possible worlds. Because knowledge ( $a$ la barn-façade cases) is undermined by environmental luck, Kate fails to know the relevant causal proposition, but does she also thereby fail to understand? Pritchard thinks not:

For while [Kate] surely can't acquire an understanding of what caused the chemical reaction by using a malfunctioning instrument which only happens to produce the right result, remember that in the second case the instrument being used is not in fact malfunctioning at all, but rather working just as it is supposed to. So what barrier would there be to [Kate] gaining understanding in this case (unless, of course, one is already convinced that understanding requires the corresponding knowledge) (Pritchard 2010:4).

I think Pritchard is clearly right in thinking that environmental luck undermines one's causal knowledge in this case; given the way Kate formed her belief, she could have easily been wrong, and so (regardless of whether she counts as understanding) she doesn't know that oxygen caused the chemical reaction.

However, notice that it doesn't follow from this that Kate lacks knowledge in this case, or that understanding-why doesn't require knowledge. There is very plausibly some item of knowledge Kate 
does possess in this case, and without which, she would fail to count as understanding why. She knows, for example, that there was a chemical reaction. She would fail to qualify as understanding why oxygen caused the chemical reaction if she didn't know that the chemical reaction occurred ${ }^{39}$. This item of knowledge isn't undermined by environmental luck in Kate's case (as she couldn't easily have been wrong about that), even if she fails to know the relevant causal proposition.

In sum, then: even if we grant Pritchard that, for some explanandum $x$, understanding-why $x$ doesn't require causal knowledge, it's still plausible to think that understanding-why does essentially involve knowledge of a more basic proposition, namely, knowledge that the relevant event in question occurred. In slogan form: regardless of whatever else understanding-why involves ${ }^{40}$, constitutive of understanding why $x$ is knowing that $x^{41}$.

To see how KTR motivates a truth-relativist semantics for understanding-why, even on Pritchard's cognitive achievement account of understanding why, let's suppose, for reductio, that (i) a truth-relativist semantics are germane to propositional knowledge, but (ii) not to (Pritchard-style)

${ }^{39}$ There are two ways one might attempt to demonstrate this point. The first will involve an appeal to the idea that one's knowledge-that something is so constitutes part of the epistemic basis of one's understanding-why something is so, such that: when this basis is undermined, then so is the understanding-why in question. To appreciate this point, let's suppose a fireman merely suspects truly that a house burnt down (but falls short of knowing that the house burnt down); suppose further that the salient explanation being entertained by the fireman is that faulty wiring caused the fire. If understandingwhy $x$ did not entail knowing-that $x$, and accordingly, the fireman could count as understanding-why the house burnt down in virtue of merely (correctly) suspecting that it did (while additionally entertaining a correct explanation), we would risk collapsing any distinction between understanding-why something is so, and merely (as when one's conspiracy theory happens to be right) possessing accurate, intelligible explanation for why something is so, when one fails to know that it is so in the first place. A different way to support the suggestion that understanding-why $\mathrm{x}$ entails knowing that $\mathrm{x}$ will be via appeal to what DeRose (1992) as well as Pritchard (in other work) have called the "past-self" test. Suppose that Kate from Pritchard's example case comes to find out that her belief that there was a chemical reaction in the first place (never mind what caused it) was a belief she held on the basis of a hallucination, and which only happened to be true. In this instance, would she regard her past self as understanding why the chemical reaction occurred (in light of learning this new information-viz., that she didn't in fact know that the reaction occurred?) It seems very unlikely. This is not, however, the reaction we would predict were understanding-why $\mathrm{x}$ compatible with a lack of knowledge-that $\mathrm{x}$. Thanks to the journal's Associate Editor for requesting some additional support here.

${ }^{40}$ This point is amenable to recognizing that understanding-why might essentially involve a kind of knowledge-how, construed as an ability. The point I'm making here, in slogan form, is compatible with endorsing something like Grimm's account of understanding-why (and it's compatible with all three of the proposals I've considered here regarding the connection between understanding-why and knowledge).

${ }^{41}$ One might raise here a worry that proceeds as follows: if understanding why $\mathrm{x}$ occurred entails knowing that $\mathrm{x}$ occurred we should expect that if the latter propositional knowledge shows stakes-variability of a certain variety the former ought to as well and further, that this would follow from a more general principle to the effect that: if $X$ entails $Y$, where $Y$ shows certain stakes variability data of a certain sort, we should expect that $X$ would show that sort of stakes-variability, too. There are reasons to resist this general principle. Take for instance the relationship between wisdom (understood as an epistemic state) and knowledge. Plausibly, one has (theoretical) wisdom (conceived of as a particularly rich variety of objectual understanding-see here Baehr (2012)) only if one possesses knowledge; though the fact that knowledge shows certain stakes-variability would not lead us to think that the possession of theoretical wisdom is sensitive to stakes in the same way, simply because theoretical wisdom entails that one possesses knowledge. In particular, the entrenchedness of theoretical wisdom will make our attributions of this state considerably less sensitive to shifting stakes. Also at tension with the general principle is a case where (say) we endorse a Weatherson(2005)-style pragmatic-encroachment account for belief attributions, and then insist that doxastic justification, though it entails belief, is not sensitive to stakes in the way that belief is. (This is precisely the kind of account Weatherson (2005) offers.) Thanks to the Associate Editor for requesting clarification on this issue. 
understanding-why attributions. Now, I've just shown that Pritchard's cognitive achievement view, while it rejects conceiving of understanding why $x$ as a kind of knowing why $x$, must uphold at least that a constitutive element of understanding why $x$ is knowing that $\mathrm{x}$. A proponent of KTR (who does not extend a truth-relativist semantics to Pritchard-style understanding-why attributions) will thus have to say that "John knows that the house burnt down" gets a truth value only relative to its being assessed as true or false, whilst "John understands why the house burnt down" (something of which a constitutive ingredient is John's knowledge that the house burnt down) gets a truth value independent of its being assessed as true or false. This pairing of positions invites the possibility that, as assessed by some individual (say, James), "John understands why the house burnt down" is true (in virtue of assessment-insensitive truth-conditions) even though, given the standards at play the context in which James assesses whether John knows that the house burnt down, John doesn't know that the house burnt down. James accordingly would be positioned to judge both that John does and does not know that the house burnt down: A pairing of KTR with a non-truth relativist semantics for (Pritchardstyle) understanding-why generates this kind of unstable situation. This possibility is off the table, however, so long as the proponent of KTR extends a truth-relativist semantics to understanding-why attributions ${ }^{42}$.

\section{$\$ 2$. Truth-relativism for understanding-why attributions is problematic.}

It seems then that, on any of three popular accounts of understanding-why, the connection between understanding-why and knowledge is such that KTR is going to motivate (for better or worse) a truthrelativist semantics for understanding-why. This is significant insofar as we are interested in the ramifications of KTR in epistemology. Perhaps there are many other ramifications; I've attempted to outline in the previous section what I take to be a substantial one ${ }^{43}$.

In this section, I want to suggest that this commitment of a proponent of KTR-a truthrelativist semantics for understanding-why attributions-is for worse, not better. I offer two kinds of considerations in support of this claim.

\section{$\$ 2.1$ Understanding and degrees}

\footnotetext{
${ }^{42}$ Thanks for an anonymous reviewer for encouraging that this point be developed.

${ }^{43}$ An important direction for future research on the ramifications of KTR in mainstream epistemology is: given the close connection between knowledge and justification, in what ways does KTR (if true) circumscribe what can be said about epistemic justification, rationality and intellectual virtue?
} 
As Grimm (2005: 36) notes, one of the most striking distinctions between knowledge and understanding is that understanding, unlike knowledge, admits of degrees. ${ }^{44}$ As Riggs (2009) points out:

both the degree of explanatory coherence ${ }^{45} \ldots$ as well as the amount of information present in someone's understanding can vary (2009: 7).

This is evidenced by our practice of attributing understanding. Consider, for instance, Grimm's suggestion that while "The novice mechanic understands a car engine passably, the expert understands it forwards and back" (2005: 36). Grimm remarks elsewhere that while one's son might have "some understanding" of the cause of a fire, "the chief has a much deeper or more sophisticated sort of understanding" (2011: 11) In both of these cases, our attributions track the gradience of understanding along the two dimensions suggested by Riggs. Consider that individuals who understand why something is the case better, or to a richer degree, than others, will typically possess not only more relevant true beliefs ${ }^{46}$ in the background, but moreover, command a richer degree of explanatory coherence between those beliefs in virtue of which (for instance) predictions ${ }^{47}$ can be made more easily and new information can be better assimilated ${ }^{48}$.

Now: to the extent that our practice of knowledge attributions is sensitive to shifting epistemic standards, it appears sensitive to such standards in a way that is very different to the way in which understanding-why ascriptions would be standards-sensitive ${ }^{49}$. If $\mathrm{S}$ knows $p$ by meeting merely lax epistemic standards, the linguistic data suggests that we simply do not attribute to $\mathrm{S}$ knowledge that $p$ (or withdraw previously attributed knowledge) when epistemic standards are raised. We don't instead attribute to $S$ a lesser degree of knowledge that $p$. This observation aligns with Pritchard's (2010) point that knowledge is prized above states that fall just incrementally short of knowledge-a suggestion that knowledge, qua epistemic state, is different in kind from that which falls incrementally short of it.

\footnotetext{
${ }^{44}$ See also Kvanvig (2003) and Elgin (2002). This is the case for both understanding-why, as well as objectual understanding (e.g. understanding some subject matter). On the manner in which the latter admits of degrees, consider Kvanvig's (2003: 201-202) remarks on the compatibility of (some) false beliefs with the understanding some subject matter.

${ }^{45}$ As Grimm (2005: 36) notes, Skyrms (1980: 140-141) outlines a similar sort of suggestion.

${ }^{46}$ See Kvanvig (2003, Ch. 8) for an argument to the effect that true beliefs that comprise one's understanding needn't meet the standards for knowledge; they could be, for instance, Gettierized.

${ }^{47}$ I discuss this element in more depth in $\$ 2.2$.

${ }^{48}$ See Carter \& Gordon (forthcoming) for a more detailed presentation on this point.

${ }^{49}$ Note that the fact that it is different is, by itself, not a problem for the truth-relativist in so far as she is committed to extending a truth-relativist semantics to understanding-why attributions). Thanks to the Associate Editor for raising this point. The problem, as I argue, turns not on the point that it is different, but the way that it is different-viz., a truthrelativist semantics for understanding-why attributions will insist that what is sensitive to the epistemic standards (at play in the context of assessing understanding-why attributions) is, specifically, the truth of these attributions. But, as I am suggesting here, truth of such attributions does not seem to shift with changing standards.
} 
Accordingly, when one's knowledge is impoverished even marginally, one is often thought to "lose" that epistemic state ${ }^{50}$.

Note that we simply don't refer to understanding as something that can be quickly or easily lost (as knowledge can be), if our epistemic position is marginally impoverished. (Compare: an epistemic state such that, whether it is present, is beholden to shifting standards, can be quickly lost, as the standards shift). That understanding is not sensitive to contextually relevant standards in the way knowledge is rationalizes our willingness to attribute it to different degrees as contexts shift-as opposed to simply withdrawing or withholding attributing (in high-standards contexts) understanding that would be attributed with laxer standards in play.

Now, in light of these observations, the problem crystallizes: a truth-relativist semantics for understanding-why attributions is clearly going to tell us that what shifts with the epistemic standards (at play in the context of assessing understanding-why attributions) is the truth of these attributions. But, we've just seen, the truth of such attributions does not seem to shift with changing standards in this way. It should be pointed out that some varieties of attributor contextualism will face this same kind of problem as the truth-relativist, insofar as the attributor contextualist aims to extend a contextualist semantics to understanding-why attributions. It should also be pointed out that, while contextualism can in principle be endorsed in a way that would not have the counterintuitive implication mentioned ${ }^{51}$, the truth-relativist (of the sort we've been considering) is going to be stuck with an implausibly strict "on-off" kind of sensitivity to the shifting of standards that (as our attribution practices suggest) would only warrant a shift in the degree to which understanding-why is attributed. So this is a strike against a truth-relativist semantics for understanding-why attributionsand, to the extent that KTR motivates a truth-relativist semantics for understanding-why attributions, a strike against KTR.

\section{$\$ 2.2$ Understanding and Demonstration}

Not only can a given agent $S$ understand why $\mathrm{x}$ to a better or worse degree than $\mathrm{S}^{\star}$, but moreover, when this difference in understanding-why is manifest, it is something we can often tell. The telltale signs in part help us to identify reliable informants: we value informants disposed to continue to be right across a spectrum of future cases, and the disposition to do so is demonstrated by individuals who not only understand why $x$ (in a minimal sort of way) but moreover can explain (as Grimm puts

\footnotetext{
${ }^{50}$ Thanks to an anonymous reviewer for encouraging this point.

${ }^{51}$ See for example, Greco's (2008) "What's Wrong with Contextualism?" in which he endorses a kind of attributor contextualism that pairs with his virtue-theoretic account of knowledge in such a way that what shifts with context is the matter of what counts as salient in a causal explanation of an agent's believing correctly; given that knowledge is defined by Greco as true belief for which one's agency is saliently causally responsible, knowledge attributions will be context-sensitive, though not in the more straightforward sense in which the truth value of knowledge attributions is directly sensitive to changes in context.
} 
it) how $\mathrm{x}$ would or would not have come about, had things been different. Accordingly, part of what explains the epistemic value of understanding-why is the ability to answer certain what-if questions (e.g. Woodward 2003; Hills 2009).

We will say then that, while the novice fireman understands why the house burnt down in virtue of his piecing together the simple connection between the fire and the faulty wiring, the novice fireman will be unable to say much more on the topic. The expert on the other hand is in a very different epistemic position: the expert has a (much) better grasp of coherence-making relations that stand between the propositions relevant to understanding why the house burnt down, and accordingly, can say more about how different explanations would be appropriate were facts in the present case manipulated. (Compare: Grimm describes this ability as akin to manipulating parts of a physical system).

Now, in light of the way in which understanding-why is, in a sense, demonstrable in this respect, a problem crops up that can be sidestepped by a contextualist semantics for understandingwhy ascriptions, though not a truth-relativist semantics. To see the problem, consider that the contextualist will typically (following DeRose (2004)) appeal to something like the shared scoreboard analogy and insist that the relevant epistemic standard in play is that which is operative in the conversational context $t^{52}$, and this standard can fluctuate during the course of the conversation as different conversational moves are made (e.g. as skeptical scenarios are introduced, or dismissed). Although (as per the previous section) the contextualist is in trouble to whatever extent she is forced to deny understanding-why in contexts where understanding-why is present (but somewhat impoverished-e.g. the novice fireman's understanding), the contextualist is nonetheless going to make the right predictions in a range of cases where understanding is demonstrated, as this demonstration will be relevant to the conversational context. For instance, by drawing attention to the expert's ability to answer a range of questions, one has made a demonstrable sort of conversational move in support of the thought that standards for understanding will be satisfied ${ }^{53}$. The truth-relativist is in a strange position with regard to the demonstration of one's understanding: it's hard to see how the epistemic standards at play in the context in which an understanding-why attribution is being assessed will be influenced by conversational moves that are salient in the context of use. In this respect, though some varieties of contextualism will face the difficulty mentioned in $₫ 2.1$, the issue raised in $\$ 2.2$ falls squarely with the truth-relativist.

\footnotetext{
${ }^{52}$ See also Sundell (2011) for a recent discussion of this issue.

${ }^{53}$ Note that this is disanalogous from (in the case of demonstrating one's knowledge) merely citing one's evidence for a proposition. This is in part because knowledge plausibly requires, though does not consist in, adducing evidence. Part of the very activity of understanding-why something is the case is engaging in the sort of grasping of coherence relations that can be demonstrated by way of answering the relevant kinds of what-if questions. Accordingly, demonstrating one's understandingwhy will be a more salient kind of conversational move than merely citing one's evidence. The former demonstration is a kind of irrefutable display of understanding that citing evidence is not, vis-à-vis, knowledge.
} 


\section{\$3. Conclusion}

It's not clear yet what a position like KTR is supposed to mean for mainstream epistemology. I've attempted to trace out some new ground here. By considering some of the ways that a truth-relativist semantics for propositional knowledge attributions will have ramification for epistemic states closely connected to propositional knowledge, I've argued that a MacFarlane-style defense of KTR motivates an extension of truth-relativism to understanding-why ascriptions. I proceeded then to suggest that such an extension will be problematic. More generally, I hope to have outlined an argumentative strategy that hints to how the correctness of a semantics for a given epistemic state must be answerable not only to the criteria of semanticists, but also to criteria uncovered only by engaging with nonsemantic debates in epistemology.

\section{References}

Baehr, J. (2012). “Two Types of Wisdom”. Acta Analytica 27 (2):81-97.

Baghramian, M. (2004). Relativism. Routledge.

Baker, C. (2012). Indexical Contextualism and the Challenges From Disagreement. Philosophical Studies, 157, 101-123.

Blome-Tillmann, M. (2009). Contextualism, Subject-Sensitive Invariantism, and the Interaction of 'Knowledge'-Ascriptions With Modal and Temporal Operators. Philosophy and Phenomenological Research, 79, 315-331.

Boghossian, P. (2006). Fear of Knowledge. Oxford: Clarendon Press.

Brogaard, B. (2005). I Know. Therefore, I Understand.

Carter, J.A. (2013). Relativism, Disagreement and Doxastic Revision. In Erkenntnis special issue on Disagreements, eds.

Cohnitz, D. \& Marques, T. 10.1007/s10670-013-9450-7

Carter, J.A. \& Gordon, E.C. (Forthcoming). Objectual Understanding and the Value Problem. Forthcoming in American Philosophical Quarterly.

Cappelen, H., \& Hawthorne, J. (2009). Relativism and Monadic Truth. Oxford: Oxford University Press.

de Regt, H. (2009). Intelligibility and Scientific Understanding. In H. de Regt, S. Leonelli, \& K. Enger, Scientific

Understanding: Philosophical Perspectives (pp. 21-42). Pittsburgh: Pittsburgh University Press.

de Regt, H., \& Dieks, D. (2005). A Contextual Approach to Scientific Understanding. Synthese, 144, 137-70.

DeRose. (1995). Solving the Skeptical Paradox. Philosophical Review, 104(1), 1-52.

DeRose, K. (1992). Contextualism and Knowledge Attributions. Philosophy and Phenomenological Research, 52(4), 913-929.

Dreier, J. (2009). Relativism (and Expressivism) and the Problem of Disagreement. Philosophical Perspectives.

Dreyfus, H. (2005). Overcoming the Myth of the Mental: How Philosophers Can Profit From the Phenomenology of Everyday Expertise. APA Pacific Division Presidential Address.

Egan, A. (2007). Epistemic Modals, Relativism and Assertion. Philosophical Studies, 133: 1-22., 1-22.

Egan, A., Hawthorne, J., \& Weatherson, B. (2005). Epistemic Modals in Context. In G. Peter, \& G. Preyer (Eds.), Contextualism in Philosophy: Knowledge, Meaning and Truth (pp. 131-170). Oxford: Oxford University Press.

Feyerabend, P. (1975). Against Method. London: Verso.

Francén, R. (2010). No Deep Disagreement for New Relativists. Philosophical Studies, 151, 19-37.

Glick, E. (2012). Abilities and Knowledge-How Attributions. In J. Brown, \& M. Gerken (Eds.), Knowledge Ascriptions. Oxford: Oxford University Press.

Gordon, E. (2012). Is There Propositional Understanding? Logos \& Episteme, 3(2), 181-192.

Graff Fara, D. (2000). Shifting Sands: An Interest-Relative Theory of Vagueness. Philosophical Topics, 28(1), 45-81.

Greco, J. (2008). What's Wrong With Contextualism? The Philosophical Quarterly, 58(232), 416-436.

Grimm, S. (2010). Understanding. In S. Bernecker, \& D. Pritchard (Eds.), Routledge Companion to Epistemology. New York: Routledge.

Grimm, S. (Forthcoming). Understanding as Knowledge of Causes. In A. Fairweather (Ed.), Virtue Scientia: Essays in Philosophy of Science and Virtue Epistemology. Springer.

Hacking, I. (1982). Language, Truth and Reason. In Rationality and relativism (pp. 48-66.). Cambridge: MIT Press.

Hacking, I. (2002). Historical Ontology. Cambridge, M.A.: Harvard University Press.

Hawthorne, J. (2004). Knowledge and Lotteries. Oxford: Oxford University Press.

Hills, A. (2009). Moral Testimony and Moral Epistemology. Ethics, 120, 94-127.

Hintikka, J. (1975). Different Constructions in Terms of the Basic Epistemological Verbs. In The Intentions of Intentionality and Other New Models for Modalities (pp. 1-25). 
Khalifa, K. (2013). Is Understanding Explanatory or Objectual. Synthese, 190(6), 1153-1171.

Kölbel, M. (2002). Truith Without Objectivity. London: Routledge.

Kölbel, M. (2003). Faultless Disagreement. Proceedings from the Aristotelian Society, 104, 53-73.

Kuhn, T. (1962). The Structure of Scientific Revolutions. Chicago: University of Chicago Press.

Kvanvig, J. (2003). The Value of Knowledge and the Pursuit of Understanding. Cambridge: Cambridge University Press.

Lasersohn, P. (2005). Context Dependence, Disagreement and Predicates of Personal Taste. Linguistics \& Philosophy, 28, 643-86.

Lewis, D. (1980). Index, Context and Content. In S. Kanger, \& S. Öhman (Eds.), Philosophy and Grammar. Reidel.

Lewis, D. (1986). Causal Explanation. In Philosophical Papers (Vol. 2). New York: Oxford University Press.

Lipton, P. (2004). Inference to the Best Explanation. New York: Routledge.

Longworth, G. (2008). Linguistic Understanding and Knowledge. Nous, 1, 50-79.

MacFarlane, J. (2007). Relativism and Disagreement. Philosophical Studies, 132, 17-31.

MacFarlane, J. (2010). Relativism and Knowledge Attributions. In S. Bernecker, \& D. Pritchard (Eds.), Routledge Companion to Epistemology. London: Routledge.

MacFarlane, J. (2011). Epistemic Modals are Assessment Sensitive. In A. Egan, \& B. Weatherson (Eds.), Epistemic Modality. Oxford: Oxford University Press.

MacFarlane, J. (n.d.). The Assessment Sensitivity of Knowledge Attributions. In T. Gendler, \& J. Hawthorne (Eds.), Oxford Studies in Epistemology (Vol. 1, pp. 197-233). Oxford: Oxford University Press.

Pritchard, D. (2005). Epistemic Luck. Oxford: Oxford University Press.

Pritchard, D. (2008). Knowing the Answer, Understanding and Epistemic Value. Grazer Philosophische Studien, 77, 325-339.

Pritchard, D. (2010). Epistemic Relatiivsm, Epistemic Incommensurability and Wittgenstenian Epistemology. In S. Hales, Blackwell Companion to Relativism (pp. 266-285.). Blackwell.

Pritchard, D. (Forthcoming). Knowledge and Understanding. In A. Fairweather (Ed.), Virtue Scientia: Virtue Epistemology and the Philosophy of Science. Springer.

Pritchard, D. (n.d.). Knowledge, Understanding and Epistemic Value. In A. O'Hear (Ed.), Epistemology (pp. 19-43). 2009: Cambridge University Press.

Putnam, H. (1982). Reason Truth and History. Cambridge: Cambridge University Press.

Richard, M. (2004). Contextualism and Relativism. Philosophical Studies, 119(1-2), 215-242.

Rorty, R. (1995). Is Truth A Goal of Inquiry? Davidson vs. Wright. Philosophical Quarterly, 45(180), 281-300.

Ryle, G. (1946). Knowing How and Knowing That. Proceedings from the Aristotelian Society, 46.

Ryle, G. (1949). The Concept of Mind. Chicago: University of Chicago Press.

Stanley, J. (2005). Knowledge and Practical Interests. Oxford: Oxford University Press.

Stanley, J. (2011). Know How. Oxford: Oxford University Press.

Strawson, P. (1985). Skepticism and Naturalism: Some Varieties. New York: Columbia University Press.

Strevens, M. (2013). No Understanding Without Explanation. Studies in History and Philosophy of Science.

Weatherson, B. (2005). Can We Do Without Pragmatic Encroachment? Philosophical Perspectives, 19: 417-443

Weatherson. (2009). $\mathrm{E} \neq \mathrm{K}$.

Weatherson, B. (2001). Indicative and Subjunctive Conditionals. Philosophical Quarterly, 51, 200-216.

Weatherson, B. (2009). Conditionals and Indexical Relativism. Synthese, 166, 333-57.

Williamson, T. (2000). Knowledge and its Limits. Oxford: Oxford University Press.

Wittgenstein, L. (1969). On Certainty. (G. Anscombe, G. von Wright, Eds., \& G. A. Paul, Trans.) Oxford: Basil Blackwell. Zagzebski, L. (2001). Recovering Understanding. In M. Steup (Ed.), Knowledge, Truth, and Duty. New York: Oxford University Press. 